\title{
MOVILIZACIÓN, REPRESIÓN Y VOTO: Rastreando Las Claves Del REFERÉNDUM DE Autodeterminación Del 1 DE OCTUBRE DE 2017 EN CATALUNYA
}

\section{Arkaitz Letamendia ${ }^{1}$}

Resumen: Este artículo indaga en los factores que posibilitaron la celebración del referéndum de autodeterminación catalán del 1 de octubre (1-O) de 2017. Mediante la técnica de la «participación observante» y fuentes secundarias periodísticas, planteo que la peculiar combinación de tres elementos - movilización, represión y voto- ayuda a explicar por qué el referéndum del 1-O pudo celebrarse, pese a la acción legal y de las Fuerzas de Seguridad españolas que trataron de impedirlo. El trabajo subraya las consecuencias teóricas y prácticas de este evento histórico, que rompe con los mecanismos consensuales característicos de la postpolítica contemporánea.

Palabras clave: Referéndum 1-O, Catalunya, movilización política, represión

1 Doctor en Sociología (UPV/EHU) arkaitzletamendia@hotmail.com 
Resum: Aquest article indaga els factors que van fer possible la celebració del referèndum d'autodeterminació català de l'1 d'octubre (1-O) de 2017. Mitjançant la tècnica de la «participació observant» i fonts secundàries periodístiques, s'hi planteja que la peculiar combinació de tres elements - mobilització, repressió i vot-ajuda a explicar per què el referèndum de l'1-O es va poder celebrar, malgrat l'acció legal i de les Forces de Seguretat espanyoles que van mirar d'impedirlo. El treball subratlla les conseqüències teòriques i pràctiques d'aquest esdeveniment històric, que trenca amb els mecanismes consensuals característics de la postpolitica contemporània.

Paraules clau: Referèndum 1-O, Catalunya, mobilització política, repressió

Abstract: This article explores the factors that enabled the holding of the Catalan referendum on self-determination on 1 October (1-O), 2017. Based on «participant observation» and secondary sources from newspapers, it is argued that a peculiar combination of three elements-mobilization, repression and ballot-helps to explain why the 1O referendum could eventually be held, despite all court actions and despite the fact that the Spanish Security Forces tried to hold it back. The article underlines the theoretical and practical implications of this historical event departing from the consensual mechanisms which characterize our contemporary post-politics.

Keywords: 1-O referendum, Catalonia, political mobilization, repression 


\section{Introducción}

El 1 de octubre de 2017 se producía en Catalunya un referéndum de autodeterminación y una movilización popular masiva, en la que pese a la acción de las policías españolas más de dos millones de personas consiguen depositar su voto. Las imágenes de la población defendiendo con sus cuerpos los colegios electorales frente a las cargas policiales darán la vuelta al mundo. En este artículo se estudian las claves de este evento histórico, mediante la técnica de la "participación observante" (Sullivan, 2005) y el apoyo documental de fuentes secundarias, los periódicos La Vanguardia y Vilaweb.

El planteamiento de partida, que será empíricamente testado, apunta a la combinación de tres factores que posibilitan que el referéndum se lleve a cabo: la movilización multitudinaria, basada en una resistencia no-violenta y la auto-organización de base; los efectos no previstos de la represión policial, considerada ilegítima e injustificada por los y las participantes en la votación; y la percepción popular sobre la importancia de los resultados del voto, referidos a la potencial declaración de independencia de Catalunya. Las conclusiones del trabajo apuntan por un lado a sus consecuencias locales y prácticas, acerca del futuro político catalán, y por el otro a sus implicaciones más teóricas y globales, sobre su impacto en los fundamentos de la postpolítica contemporánea. Comencemos para ello indagando en cuáles son estos fundamentos contemporáneos. 


\section{Reino de España vs República Catalana, o las grietas de la postpolítica}

La postpolitica, la colaboración entre tecnócratas ilustrados y liberales multiculturalistas que sustituía mediante el "consenso" y la negociación de intereses el conflicto entre ideologías, se presentaba en las sociedades capitalistas contemporáneas occidentales como un horizonte compacto, incuestionable (Zizek, 2010). En su seno, el reconocimiento de las identidades marginales y alternativas se transforma en la verdadera lucha política; ejemplo de ello es el Reino de España contemporáneo, que después de décadas de dictadura hoy permite y acepta, de modo consensuado y tolerante, ser independentista, ser republicano o ser anticapitalista en cuanto identidad, individual o colectiva.

Esta tolerancia hacia el auto-posicionamiento identitario, estético e incluso discursivo, por muy radical que éste sea, se sitúa en un universo post-ideológico en el que las reglas de juego están predefinidas; la combinación globalmente ganadora durante los dos últimos siglos de estado-nación unificado y capitalismo, con sus diversas configuraciones y marcos legales (Jessop, 2011), define las dimensiones del tablero dentro del cual se opera políticamente. Dentro de él todo es posible, todo es defendible, todo es tolerado. Es así que en la democracia española uno pueda ser independentista sin ningún problema; quizás incluso la mayoría de un territorio lo sea. Lo que el Estado no permite es que ello se materialice políticamente. Lo hemos comprobado, más con argumentos de fuerza que con la fuerza de los argumentos, en Catalunya en 2017. Las reglas de juego imperantes se cumplen, y se hacen cumplir.

$\mathrm{Y}$ es que el escenario internacional, y más concretamente el de la Unión Europea (UE) en que nos situamos, deja poco margen de maniobra para materializar proyectos políticos transformadores. El 
horizonte de una Unión de culturas diversas, medidas sociales y solidaridades europeas que traspasase fronteras estatales se difumina; lo que se impone es una UE convertida en club de socios guiada por intereses económicos y políticos, donde sus estados miembro, al tiempo que rinden pleitesía frente al grande -los intereses del Capital-, se apoyan mutuamente frente al pequeño -véase el cierre de filas contra el proceso de autodeterminación catalán ${ }^{2}-$. Un apoyo mutuo entre estados que refleja cálculos propios y temores frente a la posibilidad de contagio de reivindicaciones colectivas; si la ilusión generada por los movimientos Occuppy o el 15-M pudo ser sofocada -Ripalda (2014) alertaba aquí sobre una juventud altamente conectada pero carente de referencias históricas-, en el caso catalán la claridad de objetivos y la perspectiva histórica, la voluntad de construir una República al margen de la Monarquía Española, dota de un plus de peligrosidad a esta movilización.

Estos temores se insertan en un contexto global que viene hoy definido por el prefijo post, signo quizás de la falta de iniciativa y creatividad para generar nuevos conceptos para la política que transforma. Al ya mencionado concepto de postpolítica habría que añadirse el contexto de la posthistoria. Tras la victoria definitiva y global del capitalismo en los años 80, Harvey (1998) advertía sobre la disolución del sentido de continuidad y memoria histórica en el seno de la lógica cultural postmoderna. De esta disolución deriva la posthistoria, donde tanto las ideologías como la propia Historia se daban por acabadas. En este escenario emergen tipos de resistencias de corte postmoderno, estéticas, audiovisuales (Letamendia, 2017); las cuales,

2 Juncker, presidente de la Comisión Europea, avisaba de que si Catalunya se convierte en independiente, "otros harían la mismo", lo que "crearía más caos" en la UE (La Vanguardia, 13/10/2017):

http://www.lavanguardia.com/politica/20171013/432019034947/juncker-sicatalunya-se-convierte-independiente-otros-harian-lo-mismo.html (consultado el 23/01/2018) 
en la actual era digital (Heidkamp y Kergel, 2017), muestran una limitada capacidad de incidencia sobre las estructuras de poder.

La Historia que no se puede transformar es la que da lugar a la posthistoria, y ésta es precisamente la del Estado-nación que ha sido, es y será; la de la Nación esencialista. En su seno operan cómodamente políticos profesionales, periodistas de grandes medios e "intelectuales" promocionados por el poder; autodenominados, en uno de los giros más contradictorios de los últimos tiempos, como "no-nacionalistas" o "anti-nacionalistas" mientras convocan manifestaciones plagadas de banderas españolas, o advierten de la posibilidad de "uso de la fuerza legítima del Estado" a quienes cuestionan la unidad nacional y actúan en consecuencia ${ }^{3}$.

El referéndum de autodeterminación de 2017 catalán emerge como un tsunami colectivo que problematiza todos estos cimientos esencialistas; cimientos que en el caso español muestran una preocupante continuidad con la época franquista. España según Ripalda (2018) fue destruida hace 80 años, y hace 40 pasó la última oportunidad de recuperación, por lo que la pregunta que hoy aflora es si hay otra hegemonía probable. La actual perdura en el tiempo, la esencia se mantiene. Un referéndum de autodeterminación cuestiona esta esencia, agrietando las bases de la postpolitica y llamando a las puertas de la Historia.

\footnotetext{
3 Véase por ejemplo el manifiesto firmado por un grupo de profesores de universidades españolas donde frente al referéndum catalán se apela al "uso de la fuerza legítima" del Estado para "salvaguardar la unidad de nación española" (El País, 26/09/2017): https://elpais.com/elpais/2017/09/25/opinion/1506357684 340819.html (consultado el 23/01/2018)
} 


\section{La tautología legalista y el Régimen del 78}

El talante ha cambiado desde la implantación del Régimen del 78 en España. La tolerancia identitaria y multicultural es ahora la norma, una característica fundamental de la postpolítica a la que nos venimos refiriendo. Durante el franquismo no se toleraba y se perseguía punitivamente ser homosexual, ser rojo, ser separatista. Ahora se tolera como identidad, pero se castiga con hasta 30 años de cárcel a la rebelde que proclama la independencia de alguna parte del territorio ${ }^{4}$. El talante por tanto cambia, pero hay ciertas reglas de juego constitutivas que perduran. Romper la unidad nacional del Estado no es posible. No lo era durante el franquismo. No lo es en el siglo XXI, porque el conjunto de leyes de la Constitución no lo permite.

Esta tautología legalista es precisamente otra de las bases que el referéndum catalán ha problematizado. La Historia, entendida como una metanarrativa dialéctica y cambiante que nos ha traído hasta el punto en que nos encontramos, se desarrolla bajo la influencia contradictoria de dos fuerzas centrífugas: la estática y la dinámica social, la conservación y el cambio, o como plantea Aguilar (2001) el orden y el desorden. La imposición de un determinado orden, de un particular estado de cosas y relaciones de poder, se basa en reglas inflexibles, que niegan aspiraciones colectivas porque hay conjuntos de leyes que no lo permiten. Estas leyes descansan en fuerzas institucionalizadas que hacen, aun en caso de desacuerdo, que se cumpla lo establecido. De esta tautología legalista emerge el orden

\footnotetext{
4 El delito de rebelión, penado con hasta 30 años de cárcel, junto con los de sedición y malversación, está en la base de la investigación abierta por la Audiencia Nacional española (y más adelante también por el Tribunal Supremo) contra los miembros del Govern catalán tras la declaración de independencia (La Vanguardia, 31/10/2017):

http://www.lavanguardia.com/politica/20171031/432503997774/lamelainvestigacion-rebelion-puigdemont-declarar.html (consultado el 23/01/2018)
} 
autoritario: las mujeres no podían votar en España hasta el año 1933 porque había una serie de leyes que no lo permitía; la afroamericana Rosa Parks no podía en 1955 sentarse en los asientos delanteros de los autobuses de la ciudad de Montgomery porque las leyes los reservaban para los ciudadanos blancos (McAdam, 1983).

Reivindicaciones, conflictos, revoluciones, procesos de liberación nacional, son tipos de procesos que enfrentan estados imperantes de cosas. Los ejemplos, como comprobaremos también con el caso catalán, siguen siendo numerosos a día de hoy. Merece pues la pena subrayar que fueron y son las luchas colectivas las que modifican los estados de cosas, si éstos son considerados injustos por una parte significativa de la población. La razón tautológica del poderoso -el estado de cosas imperante es así porque el conjunto de leyes dice que es así- debería poder confrontarse a las razones de quienes plantean escenarios alternativos. El cortocircuito popular entra aquí en escena, pudiendo provocar interferencias en la auto-reproducción del sistema.

Es por todo esto que el tsunami político del referéndum catalán ha impactado, de modo seguramente inesperado, en el actual estado de cosas ligado al conjunto de leyes del Régimen del 78, e internacionalizado un conflicto político en una parte del Reino que pasa a considerarse rebelde y conflictivo ${ }^{5}$. Y digo inesperado porque si a mí mismo hace diez años, cuando vivía en Barcelona, me hubiesen dicho que en 2017 miles de personas iban a conseguir movilizarse y votar en un referéndum de autodeterminación, con sus propios cuerpos desarmados como defensa frente a la acción de 9000 policías uniformados que trataban de impedirlo por la fuerza, seguramente no me lo hubiese creído. Pero el 1 de octubre sucedió. A continuación,

\footnotetext{
${ }^{5} \mathrm{El}$ principal punto de conflictividad política en el seno del Estado español se sitúa ahora en Catalunya. Martínez Riera y Zubiaga (2014) apuntan en este sentido a que la activación de este nuevo ciclo de protesta catalán, no violento, coincide con el fin del ciclo de violencia vasco.
} 
planteo una serie de elementos para tratar de comprender las claves de este fenómeno histórico.

\section{La construcción popular del 1-O}

Parecía habérsenos olvidado, en tantos trabajos académicos moldeados por los nuevos criterios productivistas de evaluación, un elemento de análisis que el 1 de octubre fue central: el de la coerción física que se ejerció sobre las personas que acudieron a los colegios electorales (represión). A pesar de ello, la gran mayoría de la gente que fue a los centros consiguió depositar su voto (voto); a través de una actividad política que también fue una movilización (movilización). Como trataré de mostrar en este trabajo, la peculiar combinación de estos tres factores-movilización, represión y voto- puede ayudar a comprender el éxito del referéndum de autodeterminación del 1 de octubre. Este artículo pretende así ser una aportación a la explicación de por qué la mitad de la población catalana llamada a votar el 1-O de 2017 lo hizo, pese a la amenaza por parte del Estado español de que se trataba de un acto ilegal y que sería impedido por la fuerza.

La emergencia de las consultas desde abajo: rastreando las bases para la combinación de movilización, represión y voto el 1-O

Esta narración, como toda historia en que las gentes se implican y participan, comienza desde abajo. En este caso desde una pequeña población de poco más de 8000 habitantes a $45 \mathrm{~km}$ de Barcelona, Arenys de Munt. Aquí se producía el 13 de septiembre de 2009 una primera consulta sobre la independencia de Catalunya de ámbito municipal -una iniciativa popular, simbólica, no vinculante- cuyas 
consecuencias sociopolíticas se irán desencadenando hasta acabar en la jornada histórica del 1-O de $2017^{6}$.

La iniciativa popular de Arenys de Munt supone un punto de partida, de ámbito municipal, que inmediatamente se extiende a lo largo de toda Catalunya. A partir de aquí las experiencias consultivas se diseminan por todo el territorio: Muñoz y Guinjoan (2013) apuntan a que entre septiembre de 2009 y abril de 2011 alrededor de un centenar de municipios catalanes celebran este tipo de referéndums, en los que participan más de 800000 personas. Estos autores subrayan cuatro factores a la hora de explicar el grado de movilización de estas dinámicas: los recursos disponibles por el movimiento social promotor, la intensidad de los esfuerzos de movilización, la tradición participativa de los municipios y el sentimiento nacionalista en cada localidad. El factor de la movilización emerge por tanto como un elemento clave en este proceso desde sus inicios, de la mano de grupos de base y diversas organizaciones de movimiento social como la ANC (Assamblea Nacional Catalana), Ómnium Cultural, y más adelante los CDR (Comitès de Defensa de la República).

El proceso se desarrolla también a nivel institucional. Tras la sentencia de 2010 del Tribunal Constitucional español en que se declaran inconstitucionales 14 artículos del Estatut d'autonomía aprobado por el Parlament catalán en 2006, las movilizaciones y demandas de autodeterminación se hacen más potentes y masivas (Líndez Borrás, 2013). Estas demandas cristalizan a nivel de política institucional: el 27 de septiembre de 2012 el Parlament aprueba una resolución en que propone celebrar un referéndum de autodeterminación en todo el territorio de Catalunya. Como resultado

6 Información más detallada sobre este evento de Arenys de Munt puede consultarse en Wikipedia:

https://es.wikipedia.org/wiki/Consulta sobre la independencia de_Catalu $\%$ C3\%

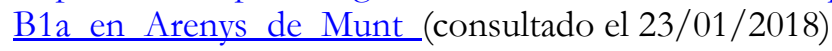


se programa una consulta no referendaria para el 9 de noviembre de 2014, y una iniciativa legislativa para negociar con el gobierno central un acuerdo para consolidarlo dentro del marco constitucional existente (Serrano, 2014). El Tribunal Constitucional suspende cautelarmente la consulta, ante lo cual la Generalitat plantea como alternativa el "Proceso participativo sobre el futuro político de Catalunya". Éste tiene como objetivo conocer la opinión de la ciudadanía sobre si Catalunya debería ser un Estado, y si ese Estado debería ser independiente. El proceso participativo se lleva a cabo el 9-N de 2014, y en él 2’3 millones de personas toman parte. El 80’76\% vota a favor de que Catalunya sea un Estado independiente ${ }^{7}$.

En un margen de menos de una década Arenys de Munt y el 9-N marcan sendos hitos participativos que conducen hasta el referéndum del 1 de octubre de 2017. En este caso se trata de un referéndum de autodeterminación convocado por la Generalitat de Catalunya, mediante la Ley 19/2017, o "ley del referéndum", aprobada en el Parlament el 6 de septiembre. Ésta establece que el referéndum es vinculante, y que se proclamará la independencia de Catalunya en caso de obtenerse más votos del "sî" que del "no". La percepción por tanto de una parte de la ciudadanía de que cada voto sirve para implementar una decisión política de trascendencia histórica, que pueda dar paso a la construcción de una República Catalana, se hace presente. No se trata simplemente de un acto puramente simbólico o de activación popular, sino de proyectar la materialización de una nueva estructura política a través de la votación popular. Así, el 1-O la gente que acude a los colegios electorales quiere votar para decidir en este proceso, y peleará por ello. Aquí el factor de la percepción del voto, con efectos

${ }^{7}$ Estos datos han sido obtenidos de Wikipedia:

https://es.wikipedia.org/wiki/Proceso participativo sobre el futuro pol $\% \mathrm{C} 3 \% \mathrm{~A}$ Dtico de Catalu\%C3\%B1a de 2014 (consultado el 23/01/2018) 
políticos vinculantes, emerge como un elemento central para interpretar este proceso.

Un último punto a resaltar tiene que ver con las medidas coercitivas adoptadas por el Estado. El Gobierno español se niega a permitir que el referéndum se celebre por considerarlo ilegal, frente a lo cual los impulsores de la votación se auto-organizan por barrios, pueblos y ciudades para llevarlo a cabo. Esta auto-organización popular posibilita que las urnas y papeletas de votación, que las policías españolas tratan de interceptar, arriben a través de voluntarios de un modo semi-clandestino a los centros electorales el día del referéndum ${ }^{8}$. El 1-O, 9000 miembros de la Policía Nacional y la Guardia Civil intervienen en los colegios electorales para impedir que las votaciones se realicen. 2,28 millones de personas consiguen depositar su voto (Pastor, 2017); pero el balance final de las cargas policiales deja según el Servei Català de la Salut más de 1000 heridos en centros de votación de toda la geografía catalana9. Además, tanto antes como después del $1-\mathrm{O}$ se producen numerosos registros policiales, imputaciones y detenciones relacionadas con el proceso ${ }^{10}$; a raíz de las cuales el propio President de la Generalitat Puigdemont ha

8 Para una información más detallada sobre cómo se hicieron llegar clandestinamente las urnas a los centros de votación puede consultarse el siguiente artículo de La Vanguardia (1/10/2017):

http://www.lavanguardia.com/politica/20171001/431694312292/urnas-

referendum.html (consultado el 23/01/2018)

${ }_{9}$ Puede verse el informe completo de heridos elaborado por el Servei Català de la Salut en: http://premsa.gencat.cat/pres fsvp/docs/2017/10/20/11/15/232799c8755f-4810-ba56-0a5bbb78609c.pdf (consultado el 23/01/2018)

${ }^{10}$ Los informes de Amnistía Internacional (2/10/2017) y Human Rights Watch (12/10/2017) aluden a un "uso excesivo de la fuerza" por parte de la policía el 1-O, mientras que el informe "El minotaure del 78" (5/12/2017) encargado por la CUP realiza un análisis más exhaustivo de "la violencia institucional del Estado español contra el proceso de autodeterminación de Catalunya". 
de exiliarse a Bélgica. El factor que aquí emerge, como elemento a tener en cuenta para interpretar los sucesos del 1-O, es el de la represión.

\section{Contextualizando el referéndum de autodeterminación: el efecto de las fallas estructurales}

Observamos cómo movilización, represión y voto emergen como factores a tener en cuenta para interpretar el proceso y la jornada del 1-O. Asimismo, el contexto histórico ha de ser el propicio, por lo que conviene indagar, desde una perspectiva sociológica, en las condiciones estructurales que posibilitan que este proceso popular pueda suceder. En este punto vale fijarse en autores como McAdam (2002) y Tilly (2007), quienes plantea cómo cambios estructurales profundos -crisis económicas y políticas, variaciones demográficas, realineaciones políticas- dan paso a nuevas expresiones de acción colectiva. La sacudida estructural de la crisis financiera global de 20072008 deja sus marcas, y de sus grietas emanan reivindicaciones que expresan de diferentes maneras su disconformidad con las condiciones socioeconómicas y políticas reinantes. Si la emergencia de movimientos como el 15-M y los Occuppy puede interpretarse desde esta óptica, como una respuesta colectiva en un contexto de crisis a las políticas de austeridad de los gobiernos (Della Porta, 2015), en el movimiento independentista este tipo de perspectiva tampoco habría de desdeñarse. Al fin y al cabo, una sacudida estructural global como la derivada de la crisis de 2007-2008 provoca sus réplicas, y de estas fricciones surgen cuestionamientos acerca de las instituciones socioeconómicas y políticas vigentes, incluidas las referidas a la naturaleza del propio Estado-nación.

Fricciones económicas y políticas, y respuestas populares: los cleavages capital-trabajo y centro-periferia (Lipset y Rokkan, 1967) se entrelazan bajo esta perspectiva. La noción de cleavage como eje 
profundo de confrontación conduce a identificar movimientos sociopolíticos en función de la estructura de poder y tipo de conflicto del que surgen (Aguilar, 2011). Éste es el caso del movimiento independentista en función del eje centro-periferia (Díez Medrano, 1999; Letamendia, 1997); o las luchas de clase conectadas con las condiciones socioeconómicas del capitalismo (Marx y Engels, 1997), así como las más recientes movilizaciones del precariado (Standing, 2013) y protestas anti-austeridad (Della Porta, 2015). La relación estructural entre ejes profundos de confrontación y protestas sociales, la presencia de una ligazón subterránea que vincula ejes de conflicto y movimientos populares, emerge a la superficie a partir de este modelo. En el caso catalán la combinación de dos fallas, la crisis socioeconómica y la política, supone una base estructural en que la acción colectiva pro-autodeterminación que venimos abordando puede suceder. Subirats y Vilaregut (2014) aluden en este sentido al establecimiento de vasos comunicantes entre crisis económica y auge de lo que denominan "independentismo/soberanismo catalán”.

Esta perspectiva estructural, la relación entre crisis económica y política y el auge del movimiento independentista, ha sido también apuntada por autoras como Bladé Costa (2015). Más allá de la identidad y los cálculos económicos, en el contexto del ciclo de protesta desencadenado por la crisis esta autora subraya la aparición y revitalización de toda una serie de redes y discursos que tratan de romper con el statu quo. Estos nuevos marcos rupturistas conectan con la orientación política, también rupturista, del independentismo, el cual se vuelve más inclusivo y transversal. En estas circunstancias es factible interpretar la emergencia de un movimiento popular de abajo hacia arriba, que apoya la celebración del referéndum de independencia (Guibernau, 2013).

Esta óptica estructural, que dibuja el contexto propicio para las reivindicaciones populares de autodeterminación catalanas, conecta a 
pie de calle con los tres elementos -movilización, represión y votoseñalados. La combinación que sucede el 1-O de 2017 entre las condiciones macro y la materialización a nivel micro, a nivel de vivencias personales de quienes participan en el referéndum, requiere ser testada empíricamente. La perspectiva de la "participación observante” (Kaminsky, 2010; Sullivan, 2005) puede servir para este propósito.

\section{Abordaje empírico a través de la "participación observante"}

Hay ocasiones en que ciertas vivencias personales, impactantes, sirven de base para construir el análisis. La "participación observante", u “observant participation” (Sullivan, 2005), parte de esta premisa: la participación en un evento de movilización política, de cuya experiencia deriva la información necesaria para indagar en el fenómeno estudiado. Esta propuesta no debe confundirse con la técnica etnográfica de la "observación participante" (Howell, 1973), en que se preparan con antelación y de un modo más o menos estructurado las diversas fases de análisis para llevar la investigación a cabo. La aproximación empírica que a continuación planteo para profundizar en el estudio se basa en las experiencias que viví en primera persona el 1-O entre las 8:30 de la mañana y las 22:00 en un colegio electoral de Barcelona, de donde extraigo los "datos" para el análisis siguiendo el modelo de "participación observante" expuesto por Sullivan $(2005)^{11}$. A ello se le suman fuentes secundarias, a través de referencias a dos periódicos catalanes, La Vanguardia y Vilaweb.

\footnotetext{
${ }^{11}$ En mi caso se trata de una participación en el evento a través de la experiencia en un centro de votación en el que, sin embargo, no puedo votar ya que no soy ciudadano catalán ni resido en este territorio.
} 
Así, ésta que sigue es una crónica en primera persona de lo que allí sucedió.

\section{1-0 de 2017: crónica desde Barcelona}

La noche anterior al 1 de octubre no fue fácil. La inquietud ante lo que estaba por venir, la amenaza de intervención de miles de policías españoles apostados en el puerto de Barcelona, no hacía fácil conciliar el sueño. El temor y la ilusión frente a una jornada que se intuía histórica se entremezclaban en una montaña rusa de emociones. En mi caso la compañía de personas queridas, con las que compartir la experiencia y arroparse mutuamente, suponía el colchón humano y el apoyo necesario para afrontar una situación de este calado. Un factor emocional que, como apunta Jasper (1998), es vital en este tipo de experiencias, en tanto que provee de motivaciones y objetivos a las y los participantes.

Tras pocas horas de sueño, alrededor de las 8:30 de la mañana de un domingo gris y ligeramente lluvioso, nos aproximamos a través de las calles semivacías de la capital catalana a un centro de votación, a la Escola de la Concepció del barrio de l'Eixample. Poco antes de llegar, un hombre adulto con cara de preocupación nos avisa de que en otro colegio a pocas manzanas de donde nos encontramos se necesita gente para proteger las urnas de una posible intervención policial. La información es confusa, y más aún para quienes no vivimos en Barcelona y nos encontramos ligeramente desorientados en medio de la ciudad, ya que el planteamiento es que haya multitud de personas en todos los colegios electorales para construir escudos humanos frente a la más que probable acción de las Fuerzas de Seguridad Del Estado (FSE). Tras unos instantes de duda, decidimos continuar el camino inicialmente previsto hacia la Escola de la Concepció. Más adelante nos enteraríamos de que ese otro colegio al que habíamos estado a 
punto de acudir era la Escola Ramón Llull, donde un hombre perdería la visión de un ojo por el impacto de una bala de goma en un escenario de cargas de la Policía Nacional ${ }^{12}$.

Pasadas las 8.30 de la mañana llegamos finalmente a la Escola de la Concepció. Al llegar al Carrer del Bruc con Aragó, en pleno barrio del Eixample barcelonés, las filas de gente que esperan para votar cubren ya todo el colegio y sobresalen por las aceras. Esta imagen contrasta con las de las calles semivacías recorridas para llegar hasta aquí. En la entrada de la escuela una multitud de personas, de diferentes edades, se unen a los padres y madres que llevan todo el fin de semana acampados en el colegio para hacer frente al cierre del mismo ${ }^{13}$. La organización continua desde el viernes de actividades diversas y talleres de los padres y madres había impedido el desalojo del centro, en tanto que los Mossos d'Esquadra (policía autonómica catalana) tenían órdenes de precintar los colegios pero sin generar problemas de orden público ${ }^{14}$. Las actividades y talleres suponen la ocupación permanente de los colegios durante dos días, permitiendo así mantener los centros activos y abiertos todo el fin de semana. A sus

12 Para más detalles sobre este suceso y la querella interpuesta por el herido contra los policías puede consultarse el siguiente artículo de Vilaweb (14/11/2017): https://www.vilaweb.cat/noticies/querella-contra-tres-policies-espanyols-del-noique-va-perdre-la-visio-dun-ull-11-o/ (consultado el 23/01/2018)

${ }^{13}$ En este artículo de Vilaweb (30/9/2017) puede leerse cómo las asociaciones de padres y madres y personas voluntarias se preparan para ocupar todo el fin de semana los colegios en diversos puntos de la geografía catalana: https://www.vilaweb.cat/noticies/actualizaciocomenca-locupacio-pacifica-acollegis-electorals-per-garantir-lobertura-diumenge/ (consultado el 23/01/2018)

${ }^{14}$ El papel de los Mossos d'Esquadra el 1-O, limitado mayoritariamente a levantar actas en los colegios ocupados, es descrito en el siguiente artículo de La Vanguardia $(01 / 10 / 2017)$ :

http://www.lavanguardia.com/politica/20171001/431691605095/mossos-

levantar-actas-colegios-electorales-ocupados-referendum-1-o.html (consultado el 23/01/2018) 
promotores se les unen ahora las y los vecinos del barrio que quieren votar, y defender que los demás puedan hacerlo.

Lo primero que sorprende al llegar al colegio electoral de esa mañana lluviosa de domingo es la transversalidad, de edad, de género, de condición social, de los allí presentes; una transversalidad propia de un barrio de clase media y trabajadora de la ciudad de Barcelona. Aún no se han cumplido las 9:00, la hora a partir de la cual se puede empezar a votar, pero según pasan los minutos cada vez más gente acude a la escuela. Poco después, una vez comenzadas las votaciones, sobre las 9:30 llegan las primeras informaciones sobre las cargas que la Policía Nacional española está realizando en la Escola Ramon Llull a unas pocas calles de donde nos encontramos. Informaciones confusas a través de dispositivos móviles y de los allí concentrados hablan de más cargas policiales en otros colegios de Catalunya, y de que el siguiente centro electoral intervenido puede ser el nuestro.

La sensación de incertidumbre aumenta al constatar desde las mesas electorales que los sistemas informáticos se están colapsando ${ }^{15}$; los avisos a los allí congregados de que es necesario apagar los teléfonos móviles o configurarlos en "modo avión" no hacen sino aumentar en unos primeros instantes la sensación de inseguridad y desconcierto generalizados. Sin embargo, ese desconcierto da rápidamente lugar a un extraño sentimiento de hermandad: si la policía va a intervenir, todos los allí presentes vamos a ser su potencial objetivo. Y eso une. Este sentimiento de hermandad y fraternidad va aumentando progresivamente a medida que más personas acuden al colegio.

15 Las sospechas de que dichos problemas informáticos pudieran deberse a la acción de la Guardia Civil tratando de cortar la conexión a Internet de los centros, son abordadas en el siguiente artículo de La Vanguardia (1/10/2017): http://www.lavanguardia.com/politica/20171001/431694965351/referendum-1ocatalunya-internet-votacion.html (consultado el 23/01/2018) 
Los problemas informáticos, pese a una multitud cada vez más numerosa, empiezan a solucionarse, y entre el gentío aparece un megáfono. A través de él un individuo de mediana edad, estratégicamente situado entre las mesas de votación y la multitud apostada a la entrada del colegio, comienza a coordinar las acciones de los allí reunidos. La consigna es clara; en caso de intervención policial entrelazarse entre todas y resistir de un modo no violento. El cuerpo en este escenario se configura como potencial recipiente físico, directo, de la represión de las fuerzas del Estado (Letamendia, 2018).

A media mañana una tensión generalizada sacude a todos los presentes en el colegio; se oyen las sirenas de una docena de furgonetas policiales de antidisturbios acercarse a toda velocidad por el Carrer Aragó. La primera reacción es la paralización debido al miedo, un primer shock -el moral shock al que se refiere Jasper (1998) - al ver aproximarse a la policía española, que rápidamente da lugar a un sentimiento visceral de coraje que se contagia colectivamente. La gente asustada al tiempo que envalentonada se aposta en todas las entradas de la escuela al grito de ¡No tenim por! (¡No tenemos miedo!); para hacer así frente, con el cuerpo desarmado como única arma, a la intervención policial que parece inminente. Sin embargo, las furgonetas de los antidisturbios no se detienen frente al colegio y pasan de largo. El susto pasa. La gente, aún en tensión, comienza poco a poco a tranquilizarse. Pero la sensación de coraje y apoyo mutuo se ha activado y se mantiene. Este sentimiento de unidad y solidaridad frente a la amenaza de intervención policial se mantendrá de hecho hasta el final de la jornada.

Mientras tanto, a medida que pasan las horas las colas para poder votar se hacen cada vez más largas y, pese a que las imágenes de las intervenciones policiales y los cientos de heridos que están causando circulan ya por redes sociales y dispositivos móviles -causando indignación entre los presentes-, se siguen acercando personas al 
colegio. A primera hora de la tarde la entrada a la escuela y las calles adyacentes se encuentran abarrotadas. Impresiona ver en medio de la aglomeración los huecos que se abren para que individuos de avanzada edad y con movilidad reducida puedan acceder al interior del colegio y votar. Las lágrimas de emoción afloran cuando las personas más mayores avanzan lentamente a través de una multitud que les abre el paso al grito de ¡Sense les iaias no hi ha revolució! (jSin las abuelas no hay revolución!). Su lento tránsito, con bastones y sillas de ruedas en muchos casos, se ve acompañado de una banda sonora colectiva de ánimo entonada por una multitud con ojos llorosos que en muchos casos no puede reprimir las lágrimas.

En la entrada del colegio se apostan, tras haber votado, mujeres y hombres, jóvenes y viejos; al tiempo que las imágenes de las cargas policiales en otros centros de votación se multiplican por los dispositivos móviles. Voluntarios y activistas traen comida y agua. Una mujer mayor, de unos sesenta años, afirma haber estado en la cercana Escola Ramón Llull donde la policía ha intervenido y requisado las urnas. Después de la intervención y las cargas policiales ha acudido al centro donde ahora nos encontramos y dice que hem de lluitar (tenemos que luchar), por una cuestión de dignidad y de democracia. Afirma estar dispuesta a volver a enfrentarse, desarmada, a la acción de las FSE. Otra mujer de similar edad comenta que lleva todo el día encontrándose en el colegio con vecinas y vecinos del barrio que conocía simplemente de vista; ahora estas personas, emocionadas por lo que se está viviendo, se interesan y se preguntan por sus vidas, haciendo así comunidad. Anécdotas e historias de personas anónimas unidas frente a la amenaza de la intervención policial, y sobre todo unidas en un sentimiento de fraternidad al saberse parte constitutiva de un evento histórico.

Avanzada ya la tarde, poco antes del anochecer se avisa desde el megáfono que es básico que la multitud permanezca entre las 8 de la 
noche, hora en que se acaban las votaciones, y las 21:30 o 22:00 en que se calcula que pueden estar contabilizados los votos. Saber los resultados de las votaciones es fundamental para las y los promotores y congregados en el colegio. Se piensa que las FSE aún pueden actuar y llevarse las urnas cuando estén llenas de papeletas para evitar que se sepan los resultados. El esfuerzo final de una jornada intensa, emocionante, y muy agotadora, se dirige ahora a rellenar con los cuerpos los huecos y entradas a la escuela más desprotegidos frente a una posible acción policial de última hora. Mientras la gente se organiza para llevar este último esfuerzo a cabo, poco antes de las 20:00 vuelven a pasar por enfrente del colegio a toda velocidad una docena de furgonetas antidisturbios. La multitud, con un coraje contagioso que ha ido incrementándose a lo largo de la jornada, se aposta en todas las entradas. Las furgonetas vuelven a pasar de largo, y esta vez parece ser la definitiva. El susto de última hora da lugar al júbilo final, y la sensación de victoria aflora ya sin tapujos.

La jornada acaba con gritos de iHem votat! (Hemos votado.) y cánticos como Els Segadors (himno catalán). Los cánticos de emoción y victoria por haber conseguido realizar el referéndum se entremezclan con sentimientos de rabia e indignación de un gentío también apesadumbrado por los cientos de heridos que las intervenciones policiales han provocado. Nadie se mueve del colegio hasta que alrededor de las 10 de la noche se saben los resultados de las votaciones; más de 3000 votos contabilizados en este centro en concreto. La información sobre los resultados se acoge con júbilo, y da paso a una nueva remesa de cánticos reivindicativos entonados al unísono. La gente, emocionada y cansada, comienza a abandonar el centro de votación con la sensación de haber contribuido a una jornada histórica. Finalmente se han depositado en toda Catalunya 2’28 millones de votos, de los cuales el $90 \% 2 \%$ opta por un sí a la independencia (Pastor, 2017). 


\section{Resultados y elementos a destacar: movilización, represión y voto}

La combinación de movilización, represión y voto para explicar el éxito del 1-O puede ser de nuevo resaltada a partir de esta aproximación empírica. Así, en primer lugar, es de destacar el papel de la movilización y la auto-organización de base. A las consultas populares organizadas a partir de 2009, siempre de la mano de organizaciones de movimiento social como la ANC y Ómnium Cultural, y desde 2017 los CDR, se les suman en las fechas próximas al 1 de octubre unas experiencias organizativas concretas barrio a barrio; un tipo de iniciativas imaginativas e innovadoras que se materializan el día del referéndum.

Estas experiencias se establecen por un lado a través de redes auto-organizadas, por barrios y pueblos, de voluntarios que consiguen hacer llegar de un modo semi-clandestino las urnas y las papeletas a los colegios electorales el 1-O. La ocupación por otro lado de los colegios durante todo el fin de semana por parte de madres y padres mediante actividades y talleres, para evitar el desalojo de los mismos, es otro ejemplo de auto-organización y coordinación en todo el territorio de Catalunya. Esta ocupación de los centros de votación supone una base espacial, física, que posibilita el referéndum.

Asimismo, la coordinación el 1-O de las acciones en el colegio vía megáfono y las consignas difundidas mediante "el boca a boca" inciden en este aspecto movilizador y auto-organizativo in situ. Autoorganización en grupos, comités y asambleas, y coordinación que sucede tanto dentro de los centros, como entre los centros de votación. Finalmente, el propio acto de participar y acudir a votar, tildado de ilegal por el Estado español y amenazado con la intervención de las FSE, podría ser considerado como una experiencia de voluntarismo, implicación y movilización masiva. 
El segundo elemento a destacar es el de la represión y sus efectos. Hemos venido observando el modo en que la represión se ejerce directamente hacia las y los promotores y participantes en el 1-O, mediante intervenciones policiales e imputaciones penales. Todas estas acciones encajan con la definición estándar de represión planteada por Davenport, que la define como la "acción reguladora del Gobierno en contra de aquellos que constituyen un desafío para las relaciones de poder existentes" (1995:683); o con el planteamiento de Opp y Roehl (1990), que se refieren a la acción punitiva de fuerzas de seguridad, tribunales y gobiernos. Sin embargo, la perspectiva sociológica propuesta por Merton (1980) sobre las "consecuencias imprevistas de la acción", en este caso policial, nos ofrece interesantes alternativas aplicables a la jornada del 1 de octubre.

Así, uno podría pensar que ante las imágenes que desde primera hora de la mañana del día del referéndum redes sociales y medios de comunicación están mostrando sobre las intervenciones policiales en los colegios electorales y los cientos de heridos, la gente se amilanaría y no acudiría a votar. Sin embargo, el 1-O ocurre justo lo contrario; a medida que la jornada avanza, progresivamente más gente se agrupa en los centros de votación. Opp y Rohel (1990) señalan ciertas condiciones en que la represión puede conducir a un aumento de los incentivos para la movilización; que ésta sea considerada por la población afectada como injusta e injustificada. Ambas consideraciones parecen combinarse en este caso.

A esta perspectiva se le suma la activación de diferentes mecanismos emocionales surgidos a nivel micro en los colegios electorales como la solidaridad grupal o la indignación. Para esta activación, además del hermanamiento físico, cara a cara, tejido en los centros de votación, el papel de los dispositivos móviles es de destacar. Éstos muestran, a veces en directo, las intervenciones que las policías españolas llevan a cabo en diversos colegios electorales, lo cual 
fortalece los sentimientos de indignación, cuidado mutuo y coraje por parte de los movilizados el 1-O. Las herramientas tecnológicas se reconvierten en este contexto en "Artefactos Culturales Audiovisuales de Reivindicación y Protesta”, o ACARP, reactivos (Del Amo, Letamendia, Diaux, 2014); capaces de mostrar a la población imágenes conflictivas más allá de los filtros impuestos por los grandes medios y por el Estado.

Además, la sensación de estar viviendo una situación injusta por parte de un sector significativo de la población catalana transforma el "miedo a la represión" en "protesta frente al miedo". La experiencia del 15-M en Barcelona había conectado los intentos de criminalización y represión de la protesta con un mayor apoyo popular al movimiento en las calles (Camps y Vergés, 2015). Ahora esta conexión parece trasladarse a la actitud de los voluntarios y votantes del 1-O, quienes pese a la amenaza policial acuden masivamente a los colegios y permanecen allí haciendo frente a la situación hasta que las votaciones acaban y se contabilizan los votos.

Precisamente la percepción de la importancia de los votos es la tercera clave para interpretar el éxito del 1-O. Se trata de un punto fundamental que conecta, una vez más, con las grietas de la postpolítica a las que nos hemos venido refiriendo en este trabajo; la gente permanece en los colegios hasta que acaba el recuento de votos porque considera que los resultados pueden servir para implementar una decisión política trascendental, para poner marcha la materialización de una nueva estructura política, de un nuevo estado. Y esto es algo que va mucho más allá de cualquier lucha o debate identitario, o acción simbólica. Si más de 2 millones de personas están dispuestas a defender con sus cuerpos el 1-O hasta el final, no es simplemente para saber cuánta gente ha acudido -como cuando se contabilizan los asistentes a una manifestación-; aquí la percepción de que las consecuencias reales, políticas, de la actividad popular podrían 
materializarse en un objetivo concreto marcan la acción. Y este objetivo, poniendo los participantes en riesgo la propia integridad física, bien debía de merecer la pena. La voluntad de decidir sobre la potencial construcción de una nueva República emerge aquí como un horizonte político que para los movilizados parece merecer la pena, hasta el punto de defenderlo no sólo simbólicamente, sino incluso corporalmente.

Esta percepción por parte de los participantes el 1-O de la importancia del voto apunta, en caso de obtenerse más votos afirmativos que negativos, hacia una declaración de independencia de Catalunya y potencial implementación efectiva de un nuevo estado. El esfuerzo movilizador y auto-organizativo de una parte significativa de la población catalana, sumado a unas consecuencias imprevistas de acción policial, permiten que la votación que dé pie a esta situación se pueda llevar a cabo. Los resultados finales del referéndum, mayoritariamente favorables al "sí", se plasman en la declaración de independencia por parte del Parlament de Catalunya, que sucede el 27 de octubre de 2017 (Vilaweb, 27/10/2017). Esta declaración sin embargo no es reconocida por el Gobierno español, y a ello le sigue la aplicación del artículo 155 de la Constitución (La Vanguardia, 27/10/2017). Esto supone la suspensión temporal de la autonomía de Catalunya, a lo que se le suma la imputación penal de los miembros del Govern catalán por delitos de rebeldía. Las consecuencias de todo este proceso, tanto locales a nivel de Catalunya, como desde un punto de vista más teórico y global, serán desarrolladas a continuación en las conclusiones del trabajo. 


\section{Conclusiones}

El 1-O la combinación de tres elementos posibilita que el referéndum de autodeterminación pueda celebrarse en Catalunya, pese a tener enfrente un Estado que utiliza diversos medios a su alcance para impedirlo. Por un lado, la movilización masiva y la auto-organización de una parte significativa de la población catalana supone la activación de una serie de redes interpersonales mediante las cuales los recursos materiales necesarios para la votación -urnas, mesas, colegios electorales- son implementados. Este carácter movilizador y voluntarista de la acción supone asimismo la convicción por parte de los participantes de que merece implicarse en la votación, y enfrentarse a las consecuencias punitivas y corporales que esta actividad pueda suponer. La voluntad de participar, por su parte, no se circunscribe a un evento de reivindicación política meramente simbólica, o a demostrar la fuerza popular de la demanda; se impone la percepción de que votar puede servir para materializar una decisión histórica, la puesta en marcha de una República Catalana al margen del Estado español. La combinación de estos elementos, sumados a una serie de mecanismos emocionales activados el 1-O a nivel micro (solidaridad, indignación), en un contexto de grupos de ciudadanos hermanados físicamente en colegios electorales frente a la amenaza de las acciones policiales, supone la fuerza moral necesaria para hacer frente a una represión cuyos efectos finales serán los no deseados; un aumento de los incentivos para la participación en el evento.

Pese al éxito del 1-O, pese a que sus promotores consiguen realizar el referéndum frente a la oposición frontal de un Estado, las consecuencias de la votación no se materializan a corto plazo en la implementación práctica de una nueva República Catalana. La aplicación del artículo 155 de la Constitución por parte del Gobierno español como respuesta a la declaración de independencia supone la 
anulación de la autonomía de Catalunya, y la destitución de todo el Govern, además de su imputación penal. La base aquí del conflicto tiene que ver con una voluntad de consulta sobre la independencia que no es constitucional, y que incide en un profundo debate político; la contraposición entre lo legal-posicionamiento defendido por el Gobierno español- y lo legítimo - planteamiento de los promotores del referéndum-.

La solución de Canadá y Reino Unido en casos similares como los de Quebec y Escocia fueron referéndums pactados, con efectos políticos vinculantes. La cultura política dominante en España, hasta el momento al menos, no contempla esta posibilidad más pragmática (y democrática) de adecuar las normas vigentes a las demandas de referéndum existentes en parte de su territorio. La tautología legalista aflora aquí de nuevo; el referéndum de autodeterminación catalán no puede realizarse porque la Ley, la Constitución española, no lo permite. No permite la votación ni la independencia de una parte de su territorio. Lo cual no deja de ser un planteamiento tautológico en sí; ninguna independencia es constitucional o legal hasta que se consigue, porque es de eso precisamente de lo que se trata, de construir un nuevo conjunto de normas políticas y legales. A día de hoy, en estas circunstancias alejadas de una voluntad de acuerdo, parece complicado materializar los resultados del 1-O y construir una República Catalana; aunque, tomando la idea del impulso y cortocircuito popular frente a la imposición legalista, tampoco está de más recordar que los movimientos de liberación nacional, en caso de conseguir sus objetivos, rara vez son a corto plazo (Anderson, 1993).

Precisamente es Anderson (1993) quien resalta el peso de las raíces populistas, de lo popular, mediante factores culturales transversales e inclusivos como la lengua, en la construcción histórica de las naciones europeas y sus estados desde comienzos del siglo XIX. Este carácter popular está presente el 1-O: la transversalidad, de edad, 
de género, de condición social de las personas reunidas en los centros de votación marca un imaginario movilizador inclusivo, donde las identidades diferenciadas quedan relegadas a un segundo plano. Incluso la identidad nacional, catalana o española, se desplaza a un segundo plano; no se trata de saber quién se siente más catalán o español, y tampoco el debate gira en torno a ser independentista catalán o ser unionista español como sentimiento o identidad. Aquí de lo que se trata es de decidir mediante votos sobre hacer o no hacer un nuevo estado, de especificar quién opta por una República Catalana o por seguir siendo parte del Reino de España.

El imaginario movilizador del $1-\mathrm{O}$ es por tanto popular, transversal, constituido por todas aquellas personas que quieren decidir sobre si construyen o no un nuevo país. Este imaginario sociopolítico popular conecta con las auto-referencias simbólicas de otras experiencias recientes, como las que derivan de la crisis neoliberal de 2007-2008 y del ciclo de protesta internacional de 2011, en las cuales según Del Amo (2017) se reformula la de idea "del pueblo" como sujeto de cambio. En las plazas ocupadas a partir de 2011 se retoma la idea populista de lo común, sin identidades particulares politizadas; así, en las experiencias de los Occuppy de Nueva York podía leerse la consigna de "somos el 99\%", mientras que los indignados del 15-M aludían a que "el pueblo unido jamás será vencido". En estos casos la base autorreferencial y simbólica apunta no tanto a las identidades diferenciadas características de los movimientos sociales surgidos en los años 60 (Del Amo, 2017), sino a un pueblo transversal, unido en la causa.

Ésta es, a su manera y con sus peculiaridades territoriales, la base popular que se constituye físicamente el 1-O en Catalunya; la de un pueblo movilizado y transversal - mujeres y hombres de diversa procedencia social- constituido por la agencia, que quiere decidir sobre su futuro político. La batalla identitaria, dominante en los 
conflictos de la posmodernidad, queda ahora relegada a un segundo plano; al tiempo que emerge un tipo de disputa que impacta en la base material de los mecanismos consensuales del Reino de España. No es una lucha cultural o identitaria lo que está (sólo) en juego, sino la voluntad de un sector amplio de la población catalana de plasmar una nueva estructura política, un nuevo estado, es decir, la voluntad de materializar políticamente un horizonte popular de carácter histórico. Una república independiente en Europa occidental en pleno siglo XXI nada menos.

En caso de plasmarse, la potencialidad de este objetivo agrietaría de raíz los fundamentos de la postpolítica contemporánea y su celebratorio consenso; plantear la ruptura de un estado es algo muy ideológico, y la base de un profundo conflicto de carácter político. La Historia dará la respuesta a si el horizonte popular, republicano y rupturista, se concreta y se materializa o no. Mientras tanto, lo que toda esta experiencia referente al $1-\mathrm{O}$ permite ya subrayar es el potencial de agencia de sus promotores, quienes parece que han decidido mirar de tú a tú al Reino de España para decidir colectivamente si quieren seguir siendo sus súbditos o no.

\section{Bibliografía}

Aguilar, Salvador (2001): Ordre i desordre. Manual d'estructura $i$ canvi de les societats. Hacer, Barcelona.

Aguilar, Salvador (2011): "La teoría de los clivajes y el conflicto social moderno", en Ibarra, Pedro y Cortina, Mercè (comps): Recuperando la radicalidad. Un encuentro en torno al análisis político crítico. Hacer, Barcelona: 209-235.

Anderson, Benedict (1993): Comunidades imaginadas. Reflexiones sobre el origen y la difusión del nacionalismo. Fondo de Cultura Económica, México D.F. 
Bladé Costa, Teresa (2015): "El moviment independentista català, més enllà de la identitat i els càlculs econòmics". Anuari del conflicte social 2014: 395-426.

Camps Calvet, Clara y Vergés Bosch, Núria (2015): “De la superación del miedo a protestar al miedo como estrategia represiva del 15M", Athenea Digital. Revista de pensamiento e investigación social, 15(4): 129-154.

Davenport, Christian (1995): "Multi-Dimensional Threat Perception and State Repression: An Inquiry into Why States Apply Negative Sanctions", American Journal of Political Science, 39(3): 683-713.

Del Amo Castro, Ion A. (2017): "El retorno del pueblo", en Díaz Cano, Eduardo y Barbeito, Roberto-Luciano (coords): XV Premio de Ensayo Breve de la Asociación Castellano-Manchega de Sociologia" Fermin Caballero": 63-85.

Del Amo, Ion A.; Letamendia, Arkaitz y Diaux, Jasón (2014): "Nuevas resistencias comunicativas: la rebelión de los ACARP", Revista Latina de Comunicación Social, 69: 307-329.

Della Porta, Donatella (2015): Social movements in times of austerity: Bringing capitalism back into protest analysis. John Wiley \& Sons, Hoboken.

Díez Medrano, Juan (1999): Naciones divididas. Clase, política y nacionalismo en el País Vasco y Cataluña. CIS, Madrid.

Guibernau, Montserrat (2013): "Secessionism in Catalonia: after democracy". Ethnopolitics 12(4): 368-393.

Harvey, David (1998): La condición de la posmodernidad. Investigación sobre los orígenes del cambio cultural. Amorrortu, Buenos Aires.

Howell, Joseph T. (1973): Hard living on Clay Street: Portraits of blue collar families. Anchor, Garden City.

Heidkamp, Birte y Kergel, David (2017): Precarity within the Digital Age. Media Change and Social Insecurity. Springer VS, Wiesbaden.

Jasper, James J. (1998): "The Emotions of Protest: Affective and Reactive Emotions in and around Social Movements", Sociological Forum, 13(3): 397-424. 
Jessop, Robert (2011): "Reflections on the State, State Power, and the World Market", en Ibarra, Pedro y Cortina, Mercè (comps), Recuperando la radicalidad. Un encuentro en torno al análisis político crítico. Hacer, Barcelona: 11-27.

Kaminsky, Marek M. (2010): Games Prisoners Play: The tragicomic worlds of Polish prison. Princeton University Press, Princeton.

Letamendia, Arkaitz (2017): "Towards the Aestheticisation of the Resistances in the Digital Age? A Critical Approach", en Heidkamp, Birte y Kergel, David (eds), Precarity within the Digital Age. Media Change and Social Insecurity. Springer VS, Wiesbaden: 135-149.

Letamendia, Arkaitz (2018): “Acciones simbólicas, conflictos materiales: la evolución contemporánea de la Forma Social de la Protesta vasca", Athenea Digital. Revista de pensamiento $e$ investigación social.

Letamendia, Francisco (1997): Juego de espejos. Conflictos nacionales centroperiferia. Trotta, Madrid.

Líndez Borràs, M. del Carme (2013): "Movilización en la sociedad catalana: aparición y pervivencia". Clivatge. Revista d'estudis $i$ testimonis sobre els conflictes $i$ els canvis socials, 2: 88-116.

Lipset, Seymour M. y Rokkan, Stein (1967): "Cleavage Structures, Party Systems and Voter Alignments", en Lipset, Seymour M. y Rokkan, Stein (eds), Party Systems and Voter Alignments: Cross National Perspective. Free Press, New York: 1-64.

Martínez Riera, Meritxell y Zubiaga, Mario (2015): "Nación y construcción estatal como acción colectiva. Un análisis comparativo de mecanismos y procesos en Cataluña y el País Vasco". Anuari del Conflicte Social 2014: 320-355.

Marx, Karl y Engels, Friedrich (1997): El manifiesto comunista. Once tesis sobre Feuerbach. Alhambra Longman, Madrid.

McAdam, Doug (1983): "Tactical Innovation and the Pace of Insurgency". American Sociological Review, 48(6): 735-754. 
McAdam, Doug (2002): "Movimientos "iniciadores" y "derivados": procesos de difusión en los ciclos de protesta", en Traugott, Mark (comp), Protesta social. Hacer, Barcelona: 243-27

Merton, Robert K. (1980): Ambivalencia sociológica y otros ensayos. EspasaCalpe, Madrid.

Muñoz, Jordi y Guinjoan, Marc (2013): “Accounting for internal variation in nationalist mobilization: unofficial referendums for independence in Catalonia (2009-11)". Nations and Nationalism, 19(1): 44-67.

Opp, Karl-Dieter y Roehl, Wolfgang (1990): "Repression, Micromobilization, and Political Protest", Social Forces, 69(2): 521-547.

Pastor, Jaime (2017): "Catalunya. Democracia vs. Estado de excepción". Tribuna Viento Sur (6/10/2017)

Ripalda, José María (2014): “Qué hacer con Marx”. Isegoría, 50: 21-35.

Ripalda, José María (2018): Filosofía en tiempo de descuento o de Hegel a la velocidad de la lu₹: Abada editores, Madrid.

Serrano, Ivan (2014): "The Evolution of the Political Discourse in Catalonia 2003-2014. From Self-Government to SelfDetermination". Open University of Catalonia, Barcelona.

Standing, Guy (2013): El precariado. Una nueva clase social. Pasado y presente, Barcelona.

Subirats, Joan y Vilaregut, Ricard (2013): "El debat sobre la independència a Catalunya. Causes, implicacions i reptes de futur". Anuari del conflicte social 2012: 514-527.

Sullivan, Sian (2005): “"We are heartbroken and furious!" Violence and the (anti)globalisation movement(s)", en Eschle, Catherine y Maiguashca, Bice (eds), Critical Theories, International Relations, and 'The Anti-Globalisation Movement': The Politics of Global Resistance. Routledge, London: 174-194.

Tilly, Charles (2007): Contienda politica y democracia en Europa, 1650-2000. Barcelona: Hacer.

Zizek, Slavoj (2010): En defensa de la intolerancia. Público, Madrid. 